\title{
The effect of intensive diabetes therapy on measures of autonomic nervous system function in the Diabetes Control and Complications Trial (DCCT)
}

\author{
The Diabetes Control and Complications Trial Research Group*
}

\begin{abstract}
Summary In the Diabetes Control and Complications Trial (DCCT), 1441 insulin-dependent diabetic patients in the primary prevention and secondary intervention cohorts were randomly assigned to either conventional or intensive therapy and followed for up to 9 years. Baseline and biennial measurements of autonomic function ( $\mathrm{R}-\mathrm{R}$ variation, Valsalva ratio, and postural testing) as well as quarterly assessment of autonomic symptoms were performed throughout the trial. There were no differences at baseline between patients randomized to intensive vs conventional therapy. In general, autonomic abnormalities increased during the trial; however, R-R variation was less abnormal in the intensively treated secondary intervention $(7 \%$ with abnormal results at 4 6 years) compared with the conventionally treated group (14\% with abnormal results, $p=0.004)$ and in the combined cohorts (5\% of intensive treatment subjects with abnormal results vs $9 \%$ of conventional treatment subjects, $p=0.0017)$. There were few ab-
\end{abstract}

normal Valsalva ratios or postural tests at baseline or during the trial. No significant difference in Valsalva ratio or postural tests occurred between the intensive and conventional treatment groups. Both the R-R variation and the Valsalva ratio had significantly greater slopes of decline over time in the patients randomized to conventional therapy (1.48 points per year and 0.015 per year, respectively) compared to those randomized to intensive therapy ( 0.912 points per year and 0.0025 per year). Of the symptoms related to autonomic function, only incomplete bladder emptying was significantly more common in the conventional group. In summary, the DCCT documented that intensive therapy can slow the progression and the development of abnormal autonomic tests. Sy [Diabetologia (1998) 41: 416-423]

Keywords AER, albumin excretion rate, Diabetes Control and Complications Trial (DCCT).
The Diabetes Control and Complications Trial (DCCT) demonstrated that intensive diabetes therapy achieving near-normal glucose control effectively delays the onset and slows the progression of longterm microvascular complications in patients with in-

Received: 5 August 1997 and in revised form: 12 November 1997

Corresponding author: The DCCT Research Group, Box NDIC/DCCT, Bethesda, MD 20892, USA

* A complete listing of the DCCT Research Group is available in Archives of Ophthalmology, 113:36-51, 1995.

Abbreviations: IDDM, Insulin-dependent diabetes mellitus; ANS, autonomic nervous system; MI, myocardial infarction; AER, albumin excretion rate. sulin-dependent diabetes mellitus (IDDM) [1]. The beneficial effect of intensive therapy was also demonstrated for clinical and electrophysiologic measurements of diabetic peripheral neuropathy $[1,2]$ as demonstrated in other clinical trials [3]. Previous clinical trials in IDDM patients addressing the question of whether cardiovascular autonomic dysfunction may be prevented or its progression retarded by intensive therapy have yielded conflicting results. Some of these studies suggested beneficial effects [4, 5] whereas others showed no benefit [6-8].

The DCCT used the following tests to assess cardiovascular autonomic nervous system function: $\mathrm{R}-\mathrm{R}$ variation, the Valsalva manoeuver, postural testing, and reported autonomic symptoms [9]. R-R varia- 
tion, Valsalva manoeuver and postural testing were considered to be particularly well-suited for a longterm clinical trial since they had been validated; shown to be reliable, reproducible, and to correlate with each other and with other tests of peripheral somatic nerve function; demonstrated to have prognostic value; and had well-established normal values [1015]. A similar combination of tests for the assessment of parasympathetic and sympathetic function has been recommended recently for use in clinical trials [15]. The DCCT used this panel of tests to evaluate the effect of intensive compared to conventional treatment on autonomic nerve function and to determine whether abnormalities of autonomic nerve function could be prevented or their progression slowed.

\section{Subjects and methods}

Study design. The DCCT design and methods have been fully described [16]. A primary prevention and a secondary intervention cohort were recruited to test whether intensive diabetes therapy could delay the onset or retard the progression of the major study outcome variable, diabetic retinopathy. At entry, the primary prevention cohort had a duration of IDDM of 1-5 years and, by design, was free of retinopathy by fundus photography and without microalbuminuria (AER $\leq 40 \mathrm{mg}$ / $24 \mathrm{~h}$ ). The secondary intervention cohort had a duration of diabetes of 1-15 years, mild-to-moderate non-proliferative retinopathy, and no more than microalbuminuria ( $<200 \mathrm{mg} / 24 \mathrm{~h})$. Diabetic neuropathy was neither an inclusion nor an exclusion criterion unless neuropathic symptoms were sufficiently severe in the opinion of the patient or the investigator to merit treatment, in which case it was grounds for exclusion. A total of 1441 subjects were recruited into the two cohorts at 29 centres from 1983 to 1989.

Patients were randomly assigned to either conventional therapy, designed to prevent symptoms of hyper- and hypoglycaemia with one or two injections of insulin per day, or to intensive therapy, designed to maintain near-normal levels of glycaemia. Intensive therapy included frequent (at least 4 per day) self-monitoring of blood glucose and either three or more injections of insulin per day or treatment with an insulin pump, adjusting insulin doses based on glucose levels, diet and exercise. Diabetic complications including neuropathy were assessed at baseline and periodically throughout the trial. Neither the investigator nor the patients were aware of study results unless predetermined safety thresholds were exceeded, at which time appropriate disclosure and treatment were undertaken [16]. The DCCT was terminated in June of 1993 when its external monitoring committee determined that the principal study question had been answered [1].

Autonomic nervous system (ANS) measurements. Three ANS tests were administered at baseline and biennially thereafter under standardized conditions $[17,18]$. Studies were performed in the morning after an overnight $(8 \mathrm{~h})$ fast requiring abstinence from food, liquids (except water), caffeine, tobacco products and all medications including over-the-counter medicines. Patients were tested after $30 \mathrm{~min}$ of supine rest in a quiet, relaxed atmosphere with the assistance of a timed respiration pacer. Patients who had experienced a hypoglycaemic episode within the past $24 \mathrm{~h}$ were rescheduled. Patients were also re- scheduled if they had consumed alcohol, engaged in unusually strenuous exercise or experienced severe emotional upset in the previous $24 \mathrm{~h}$, suffered any acute illness in the previous $48 \mathrm{~h}$ or taken any insulin in the past $8 \mathrm{~h}$ (unless they were on an insulin pump, in which case they maintained the basal infusion rate). Blood glucose level at the time of testing had to be over $2.8 \mathrm{mmol}$.

$\mathrm{R}-\mathrm{R}$ variation (heart rate variability), Valsalva manoeuver, and postural testing were recorded at each clinical site and analysed in a central ANS reading centre which has been described elsewhere [18]. Briefly, the data were read into the computer and visually scanned by a technician for quality. The data were edited where necessary, following predetermined rigid guidelines. The specially designed analysis program contained internal checks (sequential vector angle, sequential vector length, rhythm, paced breathing, aberrant cardiac beats, and cross comparison to other analysis techniques) that alerted the analysing technician to possible aberrant data which might not be apparent during visual editing. The data were certified as usable based on whether the study was performed according to the protocol, no cardiac arrhythmia was present, and the patient paced his or her breathing. All studies were reviewed a second time by the director of the reading centre. The data from each centre were obtained by means of specialized monitors prepared specifically for the DCCT by the D. E. Hokanson Co. (Bellevue, Wash., USA).

$R-R$ variation is the measurement of the magnitude of cardiac sinus arrhythmia. This is predominantly (but not exclusively) a function of the parasympathetic nervous system. R-R variation was determined as previously described [19]. The Valsalva ratio was defined as the mean of three R-R intervals after the Valsalva manoeuver (the longest R-R interval and the interval before and after it) divided by the mean of three R-R intervals during the Valsalva manoeuver (the shortest R-R interval and the intervals before and after it) $[9,11]$. The Valsalva manoeuver was done twice at each evaluation and the average of the Valsalva ratio for those two tests was used for data analysis. Postural blood pressure testing consisted of two supine measurements of blood pressure at least 6 min apart (generally before and after the R-R variation study), followed by repeated blood pressures at 1, 2, 3, 4, 5 and 10 min after standing.

Abnormal R-R variation was defined as less than 15 and an abnormal Valsalva was a ratio less than 1.50 [14, 21]. Orthostatic hypotension due to autonomic neuropathy was defined as a fall of $10 \mathrm{~mm} \mathrm{Hg}$ or greater in diastolic blood pressure confirmed by an inadequate catecholamine response to standing [11, 20-22]. A patient was considered to have abnormal ANS measurements if: 1 ) the R-R variation was less than 15 , or 2) the R-R variation was 15-19.9 and the Valsalva ratio was less than 1.50 , or 3 ) orthostatic hypotension confirmed by low catecholamines was present.

Assessment of autonomic symptoms. Every 3 months, subjects were asked about the presence or absence of various neurological symptoms or ailments using a standardized questionnaire. The following classes of symptoms were assessed as present and ascribed to diabetic autonomic neuropathy if the symptom had been present for at least 30 days and could not be attributed to other conditions: postural hypotension, gastroparesis, diabetic diarrhoea, colonic atony, genitourinary symptoms, sudomotor abnormality or hypoglycaemic unawareness [17].

As previously described [2], confirmed clinical neuropathy was diagnosed only if definite abnormalities consistent with peripheral sensorimotor neuropathy were detected on the standard exam and were confirmed by abnormal nerve conduction in at least two peripheral nerves or abnormal ANS tests or both. 
Table 1. Summary of selected baseline characteristics - all randomized patients

\begin{tabular}{|c|c|c|c|c|c|c|}
\hline & \multicolumn{3}{|c|}{ Primary prevention cohort } & \multicolumn{3}{|c|}{ Secondary intervention cohort } \\
\hline & Conventional & Intensive & Total & Conventional & Intensive & Total \\
\hline$n$ & 378 & 348 & 726 & 352 & 363 & 715 \\
\hline Age (years) & $26 \pm 8$ & $27 \pm 7$ & $26 \pm 7$ & $27 \pm 7$ & $27 \pm 7$ & $27 \pm 7$ \\
\hline Female (\%) & 46 & 51 & 48 & 46 & 47 & 46 \\
\hline IDDM duration (years) & $2.6 \pm 1.4$ & $2.6 \pm 1.4$ & $2.6 \pm 1.4$ & $8.6 \pm 3.7$ & $8.9 \pm 3.8$ & $8.8 \pm 3.8$ \\
\hline Insulin dose (IU/kg) & $0.62 \pm 0.26$ & $0.62 \pm 0.25$ & $0.62 \pm 0.25$ & $0.71 \pm 0.24$ & $0.72 \pm 0.23$ & $0.71 \pm 0.24$ \\
\hline Haemoglobin $\mathrm{A}_{1 \mathrm{c}}(\%)$ & $8.8 \pm 1.7$ & $8.8 \pm 1.6$ & $8.8 \pm 1.7$ & $8.9 \pm 1.5$ & $9.0 \pm 1.5$ & $9.0 \pm 1.5$ \\
\hline \multicolumn{7}{|l|}{ Body mass index $\left(\mathrm{kg} / \mathrm{m}^{2}\right)$} \\
\hline Male & $23.9 \pm 2.9$ & $23.3 \pm 2.5$ & $23.6 \pm 2.7$ & $23.9 \pm 2.8$ & $23.4 \pm 2.7$ & $23.6 \pm 2.8$ \\
\hline Female & $22.5 \pm 2.9$ & $22.9 \pm 3.0$ & $22.7 \pm 2.9$ & $23.4 \pm 2.9$ & $23.6 \pm 2.5$ & $23.5 \pm 2.7$ \\
\hline Current smokers (\%) & 17 & 19 & 18 & 19 & 18 & 19 \\
\hline \multicolumn{7}{|l|}{ Blood pressure $(\mathrm{mm} \mathrm{Hg})$} \\
\hline Systolic & $114 \pm 12$ & $112 \pm 11$ & $113 \pm 11$ & $116 \pm 12$ & $114 \pm 12$ & $115 \pm 12$ \\
\hline Diastolic & $72 \pm 9$ & $72 \pm 9$ & $72 \pm 9$ & $73 \pm 9$ & $73 \pm 9$ & $73 \pm 9$ \\
\hline $\operatorname{AER}(\mathrm{mg} / 24 \mathrm{~h})$ & $12 \pm 8$ & $12 \pm 9$ & $12 \pm 8$ & $19 \pm 24$ & $21 \pm 25$ & $20 \pm 25$ \\
\hline \multicolumn{4}{|l|}{ History of previous hypoglycaemic } & 4.5 & 5.8 & 5.2 \\
\hline Confirmed clinical neuropathy (\%) & 2.1 & 4.9 & 3.4 & 9.4 & 9.4 & $9.4^{\mathrm{a}}$ \\
\hline $\begin{array}{l}\text { RR-Variation } \\
\quad \% \text { Abnormal }(<15)\end{array}$ & $\begin{array}{l}48.9 \pm 21.0 \\
1.3\end{array}$ & $\begin{array}{l}49.1 \pm 22.6 \\
2.0\end{array}$ & $\begin{array}{l}49.0 \pm 21.8 \\
1.6\end{array}$ & $\begin{array}{l}45.6 \pm 22.1 \\
7.8\end{array}$ & $\begin{array}{l}47.0 \pm 22.4 \\
4.5\end{array}$ & $\begin{array}{c}46.3 \pm 22.3 \\
6.2^{\mathrm{b}}\end{array}$ \\
\hline Valsalva ratio & $2.05 \pm 0.43$ & $2.02 \pm 0.40$ & $2.03 \pm 0.42$ & $2.04 \pm 0.40$ & $2.05 \pm 0.42$ & $2.04 \pm 0.41$ \\
\hline \% Abnormal $(<1.50)$ & 6.5 & 6.6 & 6.3 & 5.2 & 5.7 & 5.5 \\
\hline $\begin{array}{l}\text { Data are mean } \pm \mathrm{SD} \text { or percent } \\
\text { a } p<0.04 \text { for total primary preve } \\
\text { vention }\end{array}$ & vs tot & hter- & $\begin{array}{l}{ }^{\mathrm{b}} p<0.05 \text { for } \\
\text { vention }\end{array}$ & l primary pr & n vs total s & dary inter- \\
\hline
\end{tabular}

Statistical analysis. Comparisons of the treatment groups were made using the Wilcoxon rank-sum test for continuous variables and Pearson's chi-squared test for categorical variables. Binary variables were compared with Fisher's exact test. Group differences in the distributions of repeated measures of continuous variables were assessed using the multivariate non-parametric test of stochastic ordering proposed by Lachin [23], weighting each of the corresponding univariate MannWhitney differences in proportion to the corresponding sample sizes.

The rates of recurrent events (e.g. individual ANS abnormalities) are presented as the number of events per 100 patient-years, calculated as the ratio of the observed number of events to the total number of patient-years of follow-up. The reduction in the event rate in the intensive therapy group is given as $100 \% \times(1-\mathrm{RR})$, where $\mathrm{RR}$ represents the ratio of the crude event rate in the intensive therapy group to that in the conventional therapy group. Confidence intervals for the rate reductions were calculated on log scales after adjusting the variances of the within-group mean rates and their ratio for possible overdispersion [24], then transformed back to the original scale.

A longitudinal model for R-R variation was fit via the technique of generalized estimating equations [25]. This technique was selected because it accounts for correlated repeated measurements with missing data points. This model was developed from a series of earlier models which were initially fit separately within each treatment group, then combined after eliminating non-significant terms. The covariates that were used in the models were the baseline values of $\mathrm{R}-\mathrm{R}$ variation, body mass index, age, duration of IDDM, and both systolic and diastolic blood pressure; indicator variables for treatment group, pres- ence of retinopathy at baseline (primary prevention cohort with none compared to secondary intervention cohort with minimal to moderate non-proliferative) and gender; time since randomization (in years); and a time-by-treatment interaction. Separate treatment-specific models were also evaluated to assess the comparability of effects in the two treatment groups.

Except as otherwise noted, results that are nominally significant at the 0.05 level are indicated without formal adjustment for multiple comparisons. Hochberg's improved Bonferroni procedure [26] was used to preserve an overall significance level of 0.05 in the closely related group of tests described in Table IV. All analyses were conducted under the principle of intention to treat, with all patients included in their originally assigned treatment group.

\section{Results}

Baseline characteristics. A summary of selected baseline characteristics of all randomized patients is shown in Table 1 . The differences in characteristics at baseline between the primary prevention and secondary intervention cohorts were expected based on the entrance criteria (e.g. duration of diabetes, presence of microalbuminuria, baseline retinopathy). As previously reported [3], confirmed clinical neuropathy was higher in the secondary intervention cohort than in the primary prevention cohort $(p<0.04)$. Similarly the percentage of patients with abnormal R-R variation was higher $(p<0.05)$ in the secondary inter- 
Table 2. Prevalence of abnormal ANS measurements at study end (percent) by length of follow-up in the DCCT

\begin{tabular}{|c|c|c|c|c|c|c|}
\hline \multirow[t]{2}{*}{ Type of abnormality } & \multirow{2}{*}{$\begin{array}{l}\text { Baseline } \\
\text { retinopathy } \\
\text { stratum }\end{array}$} & \multirow{2}{*}{$\begin{array}{l}\text { Treatment } \\
\text { group }\end{array}$} & \multicolumn{4}{|c|}{ Length of follow-up } \\
\hline & & & $\begin{array}{l}4 \text { years } \\
\text { or less }\end{array}$ & $5-6$ years & $7-8$ years & $\begin{array}{l}9 \text { years } \\
\text { or more }\end{array}$ \\
\hline $\mathrm{R}-\mathrm{R}$ variation $<15$ & $\begin{array}{l}\text { Secondary } \\
\text { Overall (all } 1\end{array}$ & $\begin{array}{l}\text { Intensive: } n= \\
\text { Prevalence (\%) } \\
\text { Conventional: } n= \\
\text { Prevalence (\%) } \\
\text { Intensive: } n= \\
\text { Prevalence (\%) } \\
\text { Conventional: } n= \\
\text { Prevalence (\%) } \\
\text { ooled) }\end{array}$ & $\begin{array}{c}52 \\
5.9 \\
39 \\
2.6 \\
0 \\
- \\
0 \\
- \\
4.5\end{array}$ & $\begin{array}{c}167 \\
4.2 \\
204 \\
5.6 \\
147 \\
7.6 \\
154 \\
14.8 \\
7.8\end{array}$ & $\begin{array}{c}68 \\
4.5 \\
65 \\
4.6 \\
110 \\
11.4 \\
109 \\
17.3 \\
10.6\end{array}$ & $\begin{array}{c}46 \\
8.9 \\
47 \\
6.4 \\
87 \\
8.3 \\
74 \\
21.9 \\
12.2\end{array}$ \\
\hline $\begin{array}{l}\mathrm{R}-\mathrm{R} \text { variation }<19 \text { and } \\
\text { Valsalva ratio }<1.5\end{array}$ & $\begin{array}{l}\text { Primary } \\
\text { Secondary } \\
\text { Overall (all }\end{array}$ & $\begin{array}{l}\text { Intensive (\%) } \\
\text { Conventional (\%) } \\
\text { Intensive (\%) } \\
\text { Conventional (\%) } \\
\text { ooled) }\end{array}$ & $\begin{array}{l}0.0 \\
0.0 \\
- \\
- \\
0.0\end{array}$ & $\begin{array}{l}0.0 \\
0.5 \\
0.7 \\
1.4 \\
0.6\end{array}$ & $\begin{array}{l}0.0 \\
0.0 \\
1.1 \\
0.0 \\
0.3\end{array}$ & $\begin{array}{l}2.6 \\
0.0 \\
1.3 \\
1.4 \\
1.3\end{array}$ \\
\hline $\begin{array}{l}\text { Confirmed orthostatic } \\
\text { hypotension }\end{array}$ & $\begin{array}{l}\text { Primary } \\
\text { Secondary } \\
\text { Overall (all }\end{array}$ & $\begin{array}{l}\text { Intensive (\%) } \\
\text { Conventional (\%) } \\
\text { Intensive (\%) } \\
\text { Conventional (\%) } \\
\text { ooled) }\end{array}$ & $\begin{array}{l}0.0 \\
0.0 \\
- \\
- \\
0.0\end{array}$ & $\begin{array}{l}0.0 \\
0.5 \\
0.0 \\
1.3 \\
0.4\end{array}$ & $\begin{array}{l}2.9 \\
0.0 \\
0.0 \\
1.8 \\
1.1\end{array}$ & $\begin{array}{l}0.0 \\
0.0 \\
1.1 \\
0.0 \\
0.4\end{array}$ \\
\hline Any abnormality & $\begin{array}{l}\text { Primary } \\
\text { Secondary } \\
\text { Overall (all }\end{array}$ & $\begin{array}{l}\text { Intensive (\%) } \\
\text { Conventional (\%) } \\
\text { Intensive (\%) } \\
\text { Conventional (\%) } \\
\text { ooled) }\end{array}$ & $\begin{array}{l}5.9 \\
2.6 \\
- \\
- \\
4.5\end{array}$ & $\begin{array}{r}4.2 \\
6.4 \\
8.2 \\
16.2 \\
8.5\end{array}$ & $\begin{array}{r}7.4 \\
4.6 \\
11.8 \\
17.3 \\
11.4\end{array}$ & $\begin{array}{r}10.9 \\
6.4 \\
9.2 \\
23.0 \\
13.0\end{array}$ \\
\hline
\end{tabular}

vention cohort (Table 1). There was no significant difference in Valsalva ratio between the two cohorts. None of the patients in the DCCT had confirmed orthostatic hypotension at baseline. At baseline, there were no significant differences between intensive and conventional treatment groups in either the primary prevention or secondary intervention cohorts, including the presence of autonomic symptoms, except for the symptom of increased urinary volume (intensive $=2.97 \%$ vs conventional $=1.37 \%, p=$ $0.04)$.

Abnormal ANS test during the DCCT. Table 2 gives the percentage of patients who developed abnormal ANS tests (as defined in "Methods") during the course of the DCCT. The great majority of these abnormalities were cases of low R-R variation; all other types of abnormality remained rare throughout the trial. The relatively small number of events makes it difficult to compare treatment groups or cohorts directly, but two patterns are apparent. Abnormalities are typically more prevalent among patients in the secondary intervention cohort and among patients followed for longer periods; the latter is most readily seen by pooling the data from all four treatment/retinopathy combinations.

$R-R$ variation results. Figure 1 illustrates the crosssectional prevalence of abnormally low $\mathrm{R}-\mathrm{R}$ variation. The data used are from the sixth annual evalua-

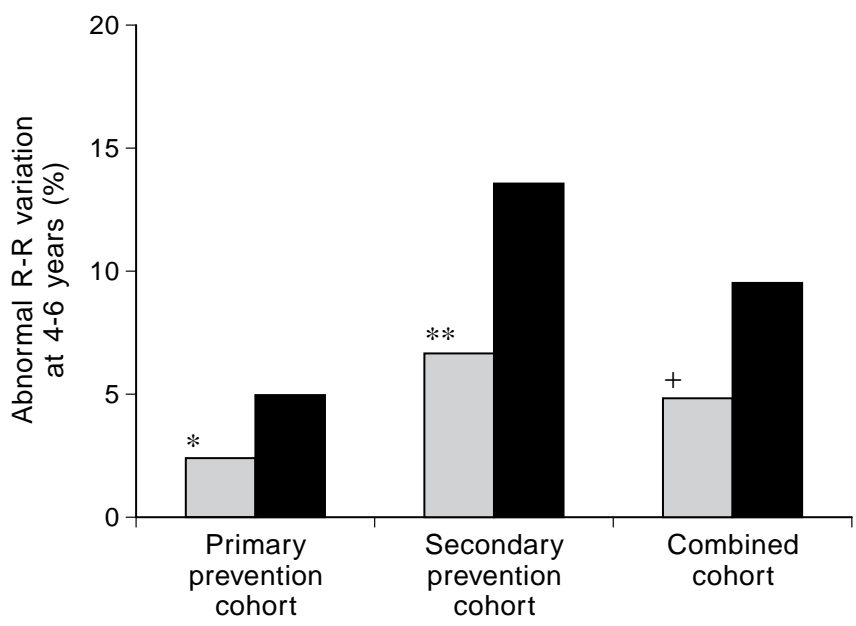

Fig. 1. Prevalence of abnormal R-R variation after 4 to 6 years of DCCT therapy. : : Intensive treatment; $\square$ Conventional treatment. $* p=0.17 ; * * p=0.0041 ;+p=0.0017$

tion of all patients followed for 6 years or more and the fourth annual evaluation of patients followed for less than 6 years. Abnormally low R-R variation was less prevalent among intensively treated patients in both the primary prevention and secondary intervention cohorts; the difference was statistically significant $(p<0.005)$ in the secondary intervention cohort, as well as in the pooled data from both cohorts combined $(p<0.002)$. However, similar comparisons within the smaller groups followed for 8 years or 
Table 3. Summary of longitudinal models for ANS characteristics overall (all patients pooled): primary and secondary strata combined

\begin{tabular}{|c|c|c|c|c|}
\hline Variable & Standard estimate & Error & $\mathrm{Z}$ & $p$ \\
\hline $\begin{array}{l}R-R \text { variation } \\
\text { Intercept } \\
\text { R-R variation at baseline } \\
\text { Age at baseline (years) } \\
\text { Baseline duration of IDDM (months) } \\
\text { Time (years): Conventional group } \\
\text { Intensive group } \\
\text { Group-by-time interaction }\end{array}$ & $\begin{array}{r}33.589 \\
0.538 \\
-0.347 \\
-0.036 \\
-1.477 \\
-0.912 \\
0.565\end{array}$ & $\begin{array}{l}2.139 \\
0.022 \\
0.056 \\
0.007 \\
0.148 \\
0.146 \\
0.160\end{array}$ & $\begin{array}{r}15.70 \\
24.61 \\
-6.22 \\
4.91 \\
9.98 \\
-6.23 \\
3.54\end{array}$ & $\begin{array}{l}0.0001 \\
0.0001 \\
0.0001 \\
0.0001 \\
0.0001 \\
0.0001 \\
0.0004\end{array}$ \\
\hline \multicolumn{5}{|c|}{$\begin{array}{lr}\text { Model mean squared error: } 271.445 & R \text {-squared: } \\
\text { Partial } R \text {-squared compared to model using only baseline R-R variation: } & 4.64 \%\end{array}$} \\
\hline Variable & Estimate & Standard error & $\mathrm{Z}$ & $p$ \\
\hline $\begin{array}{l}\text { Valsalva ratio } \\
\text { Intercept } \\
\text { Males in intensive treatment group } \\
\text { Valsalva ratio at baseline } \\
\text { Age at baseline (years): Linear } \\
\quad \text { Quadratic } \\
\text { Baseline duration of IDDM (months) }\end{array}$ & $\begin{array}{r}0.9839 \\
-0.0931 \\
0.4759 \\
0.0289 \\
-0.0005 \\
-0.0006\end{array}$ & $\begin{array}{l}0.1177 \\
0.0192 \\
0.0209 \\
0.0077 \\
0.0001 \\
0.0002\end{array}$ & $\begin{array}{r}8.36 \\
-4.85 \\
22.75 \\
3.75 \\
-3.73 \\
-4.04\end{array}$ & $\begin{array}{l}0.0001 \\
0.0001 \\
0.0001 \\
0.0002 \\
0.0002 \\
0.0001\end{array}$ \\
\hline $\begin{array}{l}\text { Body mass index at baseline }\left(\mathrm{kg} / \mathrm{m}^{2}\right) \\
\text { Time (years): Conventional group } \\
\text { Intensive group } \\
\text { Group-by-time interaction }\end{array}$ & $\begin{array}{r}-0.0086 \\
-0.0148 \\
-0.0025 \\
0.0123\end{array}$ & $\begin{array}{l}0.0029 \\
0.0034 \\
0.0051 \\
0.0040\end{array}$ & $\begin{array}{l}3.00 \\
4.28 \\
0.48 \\
3.08\end{array}$ & $\begin{array}{l}0.0027 \\
0.0001 \\
0.6306 \\
0.0021\end{array}$ \\
\hline $\begin{array}{l}\text { Model mean squared error: } 0.11975 \\
\text { Partial } R \text {-squared compared to model usir }\end{array}$ & $\begin{array}{l}R \text {-squared: } 27 \\
\text { e Valsalva ratio: } 3\end{array}$ & & & \\
\hline
\end{tabular}

Models were fit by the technique of generalized estimating equations. Results for the primary prevention and secondary intervention strata were sufficiently similar to justify combining them into a single model

more did not show significant differences (data not shown).

Table 3 describes the longitudinal model for R-R variation over time that was fit to these data as described under "Methods" above. Results in both treatment groups of both retinopathy cohorts were sufficiently similar to warrant fitting a single model to all DCCT patient results. In addition to $R-R$ variation at baseline, age and duration of IDDM (also measured at baseline) were significant predictors. The slopes of $\mathrm{R}-\mathrm{R}$ variation over time were negative and significantly different from zero in both treatment groups, indicating a general tendency of $\mathrm{R}-\mathrm{R}$ variation to decrease with time; but the decrease was significantly slower in the intensive treatment group ( 0.912 vs 1.477 points per year, $p=0.0004$ for the treatment-by-time interaction). Intercept terms differed only negligibly between the two treatment groups, so the model contains no fixed effect for treatment.

It should be noted, though, that most of the limited predictive power of this model (overall $R^{2}=39.1 \%$ ) is attributable to the patient's R-R variation at baseline: the partial $R^{2}$ compared to a model fit from baseline $\mathrm{R}-\mathrm{R}$ variation alone was only $4.6 \%$.

Valsalva ratio. Abnormal Valsalva ratios were rare throughout the trial (see Table 2). The prevalence of abnormal Valsalva ratios did not differ significantly between treatment groups in either the primary or secondary strata, or even when both strata were pooled (data not shown). The longitudinal model for Valsalva ratio described in Table 3 explained even less of the overall variation than the model for R-R variation (overall $R^{2}=27.6 \%$ ), and was similarly driven by the baseline value of the response (partial $R^{2}$ of $3.4 \%$ compared to a model using baseline Valsalva ratio alone).

In addition to baseline Valsalva ratio, significant predictors included body mass index, duration of IDDM, and a quadratic function of age (all measured at baseline). A fixed effect captured the difference in intercept for intensively treated males compared to men on conventional treatment or women in either treatment group; the intercepts estimated for these other three subgroups were indistinguishable from each other. In addition, Valsalva ratio showed a significant tendency to decrease over time in the conventional group $(0.0148$ per year, $p<0.0001)$ but not in the intensive group (estimated slope 0.0025/year, $p>0.6$ ); the difference in slopes between treatment groups was significant at $p=0.0021$.

Symptoms. Overall, there were relatively few symptoms consistent with autonomic neuropathy reported by either treatment group and few differences between conventional and intensive groups at the year 5 neurological exam (Table 4). Weakness on standing, nausea, and incomplete bladder emptying were all 
Table 4. Summary of autonomic symptoms reported on the 5th-Annual Neurologic Exam (combined cohort)

\begin{tabular}{|c|c|c|c|c|c|c|}
\hline \multirow[t]{2}{*}{ Symptom } & \multicolumn{2}{|c|}{ Conventional } & \multicolumn{2}{|l|}{ Intensive } & \multirow{2}{*}{$\begin{array}{l}\text { Test of equal } \\
\text { proportions: } \\
\mathrm{Z}\end{array}$} & \multirow{2}{*}{$\begin{array}{l}p \\
\text { (two-sided) }\end{array}$} \\
\hline & $\begin{array}{l}\text { No. of } \\
\text { Response s }\end{array}$ & $\begin{array}{l}\text { \% } \\
\text { Reporting }\end{array}$ & $\begin{array}{l}\text { No. of } \\
\text { Response s }\end{array}$ & $\begin{array}{l}\% \\
\text { Reporting }\end{array}$ & & \\
\hline \multicolumn{7}{|l|}{ Postural hypotension } \\
\hline Weakness on standing & 639 & 3.44 & 608 & 1.15 & 2.68 & 0.0073 \\
\hline Fainting on standing & 639 & 0.47 & 608 & 0.33 & 0.39 & NS \\
\hline \multicolumn{7}{|l|}{ Gastroparesis } \\
\hline Dysphagia & 639 & 0.63 & 608 & 0.49 & 0.31 & NS \\
\hline Anorexia & 639 & 0.78 & 608 & 0.33 & 1.07 & NS \\
\hline Nausea & 639 & 2.19 & 608 & 0.82 & 1.97 & 0.0486 \\
\hline Vomiting & 639 & 0.94 & 608 & 0.16 & 1.83 & NS \\
\hline Vague fullness after a meal & 639 & 2.97 & 608 & 2.63 & 0.37 & NS \\
\hline \multicolumn{7}{|l|}{ Diabetic diarrhoea } \\
\hline Nocturnal diarrhoea & 639 & 0.31 & 608 & 0.49 & -0.50 & NS \\
\hline Fecal incontinence & 639 & 0.16 & 608 & 0.00 & 0.98 & NS \\
\hline More than 20 bowel movements per day & 637 & 0.16 & 608 & 0.00 & 0.98 & NS \\
\hline \multicolumn{7}{|l|}{ Colonic atony } \\
\hline Less than 2 bowel movements per week & 639 & 1.41 & 607 & 1.15 & 0.40 & NS \\
\hline Less than 1 bowel movements in 3 days & 639 & 2.35 & 608 & 2.14 & 0.25 & NS \\
\hline \multicolumn{7}{|l|}{ Genitourinary symptoms } \\
\hline Impotence & 482 & 2.70 & 445 & 1.35 & 1.45 & NS \\
\hline Retrograde ejaculation & 458 & 0.87 & 442 & 0.47 & 0.72 & NS \\
\hline Overflow bladder incontinence & 635 & 0.16 & 603 & 0.33 & -0.62 & NS \\
\hline Urinary dribbling & 637 & 1.26 & 605 & 1.98 & -1.02 & NS \\
\hline Incomplete bladder emptying & 638 & 2.66 & 607 & 0.49 & 3.04 & $0.0023^{\mathrm{a}}$ \\
\hline Increased urinary volume & 639 & 0.94 & 608 & 0.66 & 0.56 & NS \\
\hline Decreased urinary frequency & 637 & 0.31 & 607 & 0.49 & -0.50 & NS \\
\hline \multicolumn{7}{|l|}{ Sudomotor abnormalities } \\
\hline Diminished sweating on the legs & 639 & 2.35 & 607 & 1.48 & 1.11 & NS \\
\hline Increased sweating elsewhere & 639 & 2.35 & 608 & 1.97 & 0.45 & NS \\
\hline \multicolumn{7}{|l|}{ Hypoglycaemic unawareness } \\
\hline $\begin{array}{l}\text { Decreased adrenergic awareness of } \\
\text { hypoglycaemia }\end{array}$ & 639 & 8.76 & 608 & 14.64 & -3.23 & $0.0012^{\mathrm{a}}$ \\
\hline
\end{tabular}

a Significant at an overall 0.05 level using Hochberg's procedure for multiple comparisons

more prevalent in the conventionally treated patients (two-sided $p$ values $<0.05$ ). But because of multiple comparisons, only incomplete bladder emptying reached a level which could be considered statistically significant $(p=0.0023)$. In contrast, decreased awareness of hypoglycaemia was greater in the intensive therapy group $(p=0.0012)$.

Postural hypotension. Overall, of the more than 6100 examinations for postural hypotension performed during the DCCT, there were 176 abnormal tests (diastolic decrease $>10 \mathrm{~mm} \mathrm{Hg}$ ) in 152 patients. Repeat testing on a separate day revealed that only 38 of these patients experienced a reproducible diastolic drop of more than $10 \mathrm{~mm} \mathrm{Hg}$. Catecholamines were analysed in 38 patients, and orthostatic hypotension secondary to autonomic neuropathy (i.e. low catecholamine response) was confirmed in 17 . There was no significant treatment group difference in prevalence of confirmed orthostatic hypotension ( $p=0.33$ for by Fisher's exact test).

Association of autonomic dysfunction with major macrovascular events. Only 12 patients developed major macrovascular events (confirmed myocardial infarction (MI), $n=4$; sudden death or death secondary to MI, $n=3$ ); and silent MI or angina pectoris, $(n=5)$ during the DCCT [27]. In general, there was no association with abnormal autonomic nervous system tests in these 12 individuals. Unfortunately, changes over time intervals bracketing the major macrovascular events were not consistently available due to the nature of the event itself (e.g. death) or the timing of the autonomic tests.

\section{Discussion}

The DCCT cohort was a generally young, healthy group of subjects with a relatively short duration of IDDM at baseline. During the 6.5 years average follow-up, the percentage of subjects with abnormal ANS tests nearly doubled. Most of the new abnormalities were declines in $\mathrm{R}-\mathrm{R}$ variation. It has been previously shown that the Valsalva ratio requires greater parasympathetic impairment before becoming abnormal [28] and natural history studies have shown that postural hypotension is a relatively late finding [29]. 
It appears that $\mathrm{R}-\mathrm{R}$ variation becomes abnormal early in the course of the disease, Valsalva ratio at a later time, and postural hypotension at a more advanced stage of autonomic dysfunction [28-30].

The results of the DCCT demonstrate that intensive diabetes therapy prevents, or at least retards the development of abnormal $\mathrm{R}-\mathrm{R}$ variation and slows the deterioration of $\mathrm{R}-\mathrm{R}$ variation over time. The generalised estimating equation model suggests that older age, longer duration of diabetes, and greater initial R-R variation were associated with the greatest slopes of deterioration. It has been suggested that other parameters, such as blood pressure, gender and adiposity [31-33] significantly affect $R-R$ variation. The DCCT results did not confirm these crosssectional findings.

There were relatively few subjects who developed more advanced stages of autonomic neuropathy, such as an abnormal Valsalva ratio, orthostatic hypotension or symptoms of autonomic dysfunction. Overall, less than $3 \%$ of DCCT subjects reported symptoms consistent with autonomic dysfunction. Thus, the inability to demonstrate a difference in these rare events between intensive and conventional treatment groups is not surprising.

In the DCCT there was a greater prevalence of hypoglycaemic unawareness in the intensive treatment group, which had a 3-fold greater occurrence of hypoglycaemia compared with the conventional group [34]. This is most likely secondary to changes in the glycaemic threshold for autonomic activation that occurs after hypoglycaemia $[35,36]$ rather than to autonomic neuropathy.

Previous studies have suggested that R-R variation and Valsalva ratios are often abnormal in patients with coronary artery disease. There were relatively few cardiovascular events in the DCCT and as a result it was not possible to determine the relationship between ANS function and cardiovascular events. However, the follow-up study of the DCCT cohort, The Epidemiology of Diabetes Interventions and Complications (EDIC) study [37], will be able to examine the putative relationship between ANS function during the DCCT and cardiovascular events.

In summary, as with the other long-term complications of diabetes (sensorimotor neuropathy, nephropathy, and retinopathy), intensive treatment not only prevents the development of abnormal $R-R$ variation, but also slows the deterioration of $\mathrm{R}-\mathrm{R}$ variation over time.

Acknowledgements. The DCCT is sponsored by the Division of Diabetes, Endocrinology and Metabolic Diseases of the National Institutes of Diabetes and Digestive and Kidney Diseases, the National Institutes of Health, through cooperative agreements and a research contract. Additional support was supported by the National Heart, Lung and Blood Institute, the National Eye Institute, and the General Clinical Research Program of the National Center for Research Resources.

\section{References}

1. The DCCT Research Group (1993) The effect of intensive treatment of diabetes on the development of long-term complications in insulin-dependent diabetes mellitus. $\mathrm{N}$ Engl J Med 329: 977-986

2. The DCCT Research Group (1995) The effect of intensive treatment of diabetes therapy on the development and progression of neuropathy. Annals Int Med 122: 561-568

3. Reichard P, Nilsson BY, Rosenquist U (1993) The effect of long-term intensified insulin treatment on the development of microvascular complications of diabetes mellitus. N Engl J Med 329: 304-309

4. Mogensen CE (1988) Autonomic and somatosensory nerve function after 2 years of continuous subcutaneous insulin infusion in type 1 diabetes. Diabetes 37: 452-455

5. Reichard P, Berglund B, Britz A, Cars I, Nilsson BY, Rosenqvist U (1991) Intensified conventional insulin treatment retards the microvascular complications of insulindependent diabetes mellitus (IDDM): the Stockholm Diabetes Intervention Study (SDIS) after 5 years. J Int Med 230: $101-108$

6. The St Thomas's Diabetic Study Group (1986) Failure of improved glycaemic control to reverse diabetic autonomic neuropathy. Diabet Med 3: 330-334

7. Lauritzen T, Frost-Larsen K, Larsen H-W, Deckert T, the Steno Study Group (1985) Two-year experience with continuous subcutaneous insulin infusion in relation to retinopathy and neuropathy. Diabetes 34 [Suppl]:74-79

8. Ziegler D, Dannehl K, Wiefels K, Gries FA (1992) Differential effects of near-normoglyceamia for 4 years on somatic nerve dysfunction and heart rate variation in type 1 diabetic patients. Diabet Med 9: 621-629

9. Genovely H, Pfeifer M (1988) R-R variation: the autonomic test of choice in diabetes. Diab Metab Rev 4: 255-271

10. Ziegler D (1994) Diabetic cardiovascular autonomic neuropathy: prognosis, diagnosis and treatment. Diab Metab Rev 10(4):339-383

11. Pfeifer M, Peterson H (1987) Cardiovascular autonomic neuropathy. In: Dyck PJ, Thomas PK, Asbury AK, Winegrad AI, Port D (eds) Diabetic neuropathy. W. B. Saunders Company, Philadelpia, pp 122-133

12. Schumer M, Crain Miller G, Pfeifer M, The Statil Study Group (1988) Diabetic autonomic neuropathy-part II: coefficient of variation of rr-variation and valsalva manoeuver tests. Am J Med 85 [Suppl SA]:144-146

13. Gelber D, Pfeifer M, Schumer M, The Statil Study Group (1995) Reliability and comparison of methods to calculate heart rate variability. Diabetes 44: 30A (Abstract)

14. Gelber D, Pfeifer M, Dawson B, Schumer M (1997) Cardiovascular autonomic nervous system test determination of normative values and effect confounding variables. J Auton Nerv Syst 62: 40-44

15. Clinical autonomic testing report of the therapeutics and technology assessment subcommittee of the American Academy of Neurology 1996. J AM Acad Neurol 46: 873880

16. The DCCT Research Group (1986) Design and methodologic consideration for the feasibility phase. Diabetes 35 : 530-545

17. The DCCT Research Group (1993) DCCT manual of operations. Springfield, VA, U.S. Department Of Commerce National Technical Information Service, BP 93182282

18. Schumer M, Burton G, Burton C, Crum D, Pfeifer, M, The DCCT Study Group (1988) Diabetic autonomic neuropathy-part I: autonomic nervous system data analysis by a 
computerized central unit in a multi-centre trial. Am J Med 85 [Suppl SA]:137-143

19. Weinberg C, Pfeifer M (1984) An improved method for measuring heart rate variability: assessment of cardiac autonomic function. Biometrics 40: 855-861

20. Cryer RE, Silverberg AB, Santiago JW, Shah SD (1978) Plasma catecholamines in diabetes. The symptoms of hypoadrenergic and hyperadrenergic postural hypotension. Am J Med 64: 407-416

21. Tohmeh JF, Shah SD, Cryer RE (1979) The pathogenesis of hyperadrenergic postural hypotension in diabetic patients. Am J Med 67: 772-778

22. Ziegler D, Laux G, Dannekl K, Spüler, Münlen H, Mayer P, Grier F (1992) Assessment of cardiovascular autonomic function: Age-related normal ranges and reproducibility of spectral analyses, vector analyses, and standard tests of heart rate variation and blood pressure responses. Diabet Med 9: 166-175

23. Lachin JM (1992) Some large-sample distribution-free estimators and tests for multivariate partially incomplete data from two populations. Stat Med 11: 1151-1170

24. Kleinbaum DG, Kupper LL, Morgenstein H (1982) Epidemiology research. New York: Van Nostreand Reinhold Co. pp. 296-300, 340-342 and 369

25. Zeger SL, Liang KY (1986) Longitudinal data analyses for discrete and continuous outcomes. Biometrics 42: 121-130

26. Hochberg Y (1988) A sharper Bonferroni procedure for multiple tests of significance. Biometrika 75: 800-802

27. The DCCT Research Group (1995) Effect of intensive diabetes management on macrovascular events and risk factors in the Diabetes Control and Complications Trial. Am J Cardiology 75: 894-903

28. Rothchild A, Winberg C, Halter J, Porte D and Pfiefer M (1987) Sensivity of R-R variation and valsalva ratio in as- sessment of cardiovascular diabetic autonomic neuropathy. Diabetes Care 10: 735-741

29. Ewing DJ, Campbell IW, Clarke BF (1980) The natural history of diabetic autonomic neuropathy. Q J Med New Series XLIX No. 913 95-108

30. Ziegler D, Lauz C, Danmehl K, Spiller M, Muhler H, Mavert P, Gries FA (1992) Assessment of cardiovascular autonomic function. Diabet Med 9: 166-175

31. Hilstead J, Richter E, Madsbad S et al. (1987) Metabolic and cardiovascular responses to epinephrine in diabetic autonomic neuropathy. N Engl J Med 317: 421-425

32. Pfeifer M, Dawson E, Gelber D, Schrage J, Moran M, Farquhar J, Schumer M (1994) Age, body, mass index, and mean arterial pressure significantly affect interpretation of cardiovascular autonomic nervous system tests. Diabetes 43 [Suppl 1]:57A (Abstract)

33. Peterson H, Rothschild, M, Weinberg, C, Fell R, McLeisch K, Pfeifer M (1988) Body fat and the activity of the autonomic nervous system. N Engl J Med 318: 1077-1083

34. DCCT Research Group (1993) Epidemiology of severe hypoglycemia in the Diabetes Control and Complications Trial (DCCT). Am J Med 90: 450-459

35. Amiel SA, Pottinger RC, Archibald HR et al. (1991) Effect of antecedent glucose control on cerebral function during hypoglycemia. Diabetes Care 14: 109-118

36. Boyle PJ, Kempers SF, O'Connor AM, Nagy RJ (1995) Brain glucose uptake and unawareness of hypoglycaemia in patients with insulin-dependent diabetes mellitus. N Engl J Med 333: 1726-1731

37. The Epidemiology of Diabetes Interventions and Complications (EDIC) Study Group(1994) EDIC Protocol. Rockville, MD. The Biostatistics Center, The George Washington University 